\title{
A non-cardiomyocyte autonomous mechanism of cardioprotection involving the SLO1 BK channel
}

Opening of BK-type $\mathrm{Ca}^{2+}$ activated $\mathrm{K}^{+}$channels protects the heart against ischemia-reperfusion (IR) injury. However, the location of BK channels responsible for cardioprotection is debated. Herein we confirmed that openers of the SLO1 BK channel, NS1619 and NS11021, were protective in a mouse perfused heart model of IR injury. As anticipated, deletion of the Slo1 gene blocked this protection. However, in an isolated cardiomyocyte model of IR injury, protection by NS1619 and NS11021 was insensitive to Slo1 deletion. These data suggest that protection in intact hearts occurs by a non-cardiomyocyte autonomous, SLO1-dependent, mechanism. In this regard, an in-situ assay of intrinsic cardiac neuronal function (tachycardic response to nicotine) revealed that NS1619 preserved cardiac neurons in IR injury. Furthermore, blockade of synaptic transmission by hexamethonium suppressed cardioprotection by NS1619 in intact hearts. These results suggest that opening SLO1 protects the heart during IR injury, via a mechanism that involves intrinsic cardiac neurons. Cardiac neuronal ion channels may be useful therapeutic targets for eliciting cardioprotection 


\section{PeerJ Manuscript \#2012:12:203}

A non-cardiomyocyte autonomous mechanism of cardioprotection involving the SLO1 BK channel.

Andrew P. Wojtovich ${ }^{1}$, Sergiy M. Nadtochiy ${ }^{2}$, William R. Urciuoli ${ }^{2}$, Charles O. Smith ${ }^{3}$, Morten Grunnet $^{4,5}$, Keith Nehrke ${ }^{1}$, Paul S. Brookes ${ }^{2 *}$

Departments of ${ }^{1}$ Medicine, ${ }^{2}$ Anesthesiology, and ${ }^{3}$ Biochemistry, University of Rochester Medical Center, Rochester, NY. ${ }^{4}$ Lundbeck AS, Valby, Denmark. ${ }^{5}$ Acesion Pharma, Copenhagen, Denmark.

*Corresponding author: Paul S. Brookes, PhD.

Department of Anesthesiology, Box 604

University of Rochester Medical Center

601 Elmwood Avenue,

Rochester, NY 14642, USA

Tel. (585) 273-1626

paul_brookes@urmc.rochester.edu

Running title: Slo1 \& Cardiac Neuron Protection

Word Count: 7290 (including references) 


\section{ABSTRACT}

Opening of BK-type $\mathrm{Ca}^{2+}$ activated $\mathrm{K}^{+}$channels protects the heart against ischemiareperfusion (IR) injury. However, the location of BK channels responsible for cardioprotection is debated. Herein we confirmed that openers of the SLO1 BK channel, NS1619 and NS11021, were protective in a mouse perfused heart model of IR injury. As anticipated, deletion of the Slo1 gene blocked this protection. However, in an isolated cardiomyocyte model of IR injury, protection by NS1619 and NS11021 was insensitive to Slo1 deletion. These data suggest that protection in intact hearts occurs by a non-cardiomyocyte autonomous, SLO1-dependent, mechanism. In this regard, an in-situ assay of intrinsic cardiac neuronal function (tachycardic response to nicotine) revealed that NS1619 preserved cardiac neurons following IR injury. Furthermore, blockade of synaptic transmission by hexamethonium suppressed cardioprotection by NS1619 in intact hearts. These results suggest that opening SLO1 protects the heart during IR injury, via a mechanism that involves intrinsic cardiac neurons. Cardiac neuronal ion channels may be useful therapeutic targets for eliciting cardioprotection.

\section{KEY WORDS}

Large conductance potassium channel, ischemia, reperfusion, preconditioning, NS1619, NS11021, cardiac neurons

\section{ABBREVIATIONS}

NS1619:1,3-Dihydro-1-[2-hydroxy-5-(trifluoromethyl)phenyl]-5-(trifluoromethyl)-2Hbenzimidazol-2-one

NS11021: 1-(3,5-bis-trifluoromethyl-phenyl)-3-[4-bromo-2-(1H-tetrazol-5-yl)-phenyl]-thiourea BTC-AM: Benzothiazole coumarin acetyoxymethyl ester

BK: large-conductance "big" $\mathrm{K}^{+}$channel

$\mathrm{mK}_{\text {ATP: }}$ mitochondrial ATP-sensitive $\mathrm{K}^{+}$channel

TTC: Tetrazolium chloride

WT: Wild-type 


\section{INTRODUCTION}

All tissues, including the heart, possess endogenous mechanisms to protect against ischemia-reperfusion (IR) injury, and the opening of $\mathrm{K}^{+}$channels is central to many cardioprotective paradigms including ischemic preconditioning (IPC) and anesthetic

preconditioning $(A P C)^{[1]}$. The mitochondrial $\mathrm{K}_{\text {ATP }}$ channel is perhaps the most widely associated with cardioprotection ${ }^{[2,3]}$, but a large-conductance (BK) channel encoded by the Slo gene family is also proposed to play a protective role in the heart ${ }^{[4,5]}$. The Slo encoded channels comprise 3 isoforms $(\mathrm{SLO} 1 / 2 / 3)^{[6]}$, and although a channel resembling SLO1 (K $\left.\mathrm{K}_{\mathrm{Ca}} 1.1, \mathrm{KCNMA} 1\right)$ has been reported in mitochondria ${ }^{[7]}$, gene deletion experiments show that Slo1 is not required for cardioprotection by IPC or APC ${ }^{[5]}$.

Despite ongoing debate regarding the identity of a mitochondrial BK channel, it is widely reported that SLO1 is expressed in the heart ${ }^{[8-10]}$. Furthermore, SLO1 activation by small molecules such as NS1619 and NS11021 is cardioprotective ${ }^{[11,12]}$. SLO1 is not found at the cardiomyocyte plasma membrane ${ }^{[11]}$, but SLO1 channel activity has been reported in intracardiac neurons ${ }^{[13]}$ and Purkinje fibers ${ }^{[14]}$, where it is thought to play a role in regulating heart rate $^{[15]}$.

Despite the assumption that NS1619 and NS11021 protect via a (mitochondrial) SLO1 ${ }^{[11]}$, many non-specific effects such as opening of other ion channels ${ }^{[16-18]}$ and inhibition of mitochondrial function ${ }^{[19-23]}$ have been reported for these compounds, and a pharmacogenomic study has not been conducted. Such SLO1-independent effects could underlie the cardioprotective benefit of these compounds ${ }^{[21,23]}$, and herein we sought to investigate the contribution of SLO1 to the cardioprotection elicited by NS1619 and NS11021, including studies in $\mathrm{Slo1}^{-/}$mice to control for off-target effects. We report on the discovery of a noncardiomyocyte autonomous mechanism of cardioprotection involving SLO1 and intrinsic cardiac neurons.

\section{MATERIALS \& METHODS}

Reagents, Animals 
NS11021 was a gift from Neurosearch A/S. (Ballerup Denmark). All other chemicals were of the highest grade available from Sigma (St. Louis, MO) unless otherwise specified. Slo $1^{-1}$ $\left(\mathrm{KCNMA1}^{-1}\right)$ knockout mice on the FVB background via deletion of Exon1, which contains the translation start site and the SO trans-membrane segment ${ }^{[24]}$. This results in both transcripts and protein being undetectable, and it has been previously shown that the lack of an SO domain results in a nonfunctional BK channel ${ }^{[25,26]}$. Animals were genotyped by tail biopsy PCR, as previously described ${ }^{[24]}$. All experiments used male WT and S/o1\% littermates age 6-8 weeks. Mice were maintained in an AAALAC-accredited pathogen-free barrier facility with food and water available ad libitum. All procedures were in accordance with the NIH Guide for the Care and Use of Laboratory Animals (2011 revision) and were approved by the University Committee on Animal Resources.

\section{Mouse Langendorff ex-vivo perfused heart}

Following avertin anesthesia, a thoracotomy was performed, the aorta cannulated insitu and the heart rapidly transferred to perfusion apparatus as previously described ${ }^{[5,27]}$. The heart was perfused with Krebs-Henseleit buffer in constant flow mode $(4 \mathrm{ml} / \mathrm{min})$. The following experimental protocols were observed: (i) IR injury: 20 min normoxic perfusion, 40 min global ischemia, $60 \mathrm{~min}$ reperfusion. (ii) NS1619+IR: $10 \mathrm{~min}$ normoxic perfusion, $10 \mathrm{~min}$ of $5 \mu \mathrm{M}$ NS1619, 30 sec washout, then IR as above. (iii) NS11021+IR: 10 min normoxic perfusion, $10 \mathrm{~min}$ of $500 \mathrm{nM}$ NS11021, $30 \mathrm{sec}$ washout, then IR as above.

Studies involving hexamethonium were independently controlled and the following experimental protocols were observed: (iv) IR injury: 25 min normoxic perfusion, 35 min global ischemia, 60 min reperfusion. (v) NS1619+IR: 15 min normoxic perfusion, $10 \mathrm{~min}$ of $5 \mu \mathrm{M}$ NS1619, 30 sec washout, then IR as above. (vi) NS1619+IR+Hexamethonium: 12.5 min normoxic perfusion, $2.5 \mathrm{~min}$ of $500 \mu \mathrm{M}$ hexamethonium, $10 \mathrm{~min}$ of $5 \mu \mathrm{M}$ NS1619 plus $500 \mu \mathrm{M}$ hexamethonium, $30 \mathrm{sec}$ washout of NS1619 only, $35 \mathrm{~min}$ global ischemia, $5 \mathrm{~min}$ reperfusion plus $500 \mu \mathrm{M}$ hexamethonium, 55 min reperfusion. (vii) Atpenin A5 (AA5)+IR: 5 min normoxic perfusion, $20 \mathrm{~min}$ of $10 \mathrm{nM}$ AA5, $30 \mathrm{sec}$ washout, then $\mathrm{IR}$ as above. (viii) AA5+IR+Hexamethonium: 2.5 min normoxic perfusion, 2.5 min of $500 \mu \mathrm{M}$ hexamethonium, 20 
min of $10 \mathrm{nM}$ AA5 plus $500 \mu \mathrm{M}$ hexamethonium, $30 \mathrm{sec}$ washout of AA5 only, 35 min global ischemia, $5 \mathrm{~min}$ reperfusion plus $500 \mu \mathrm{M}$ hexamethonium, $55 \mathrm{~min}$ reperfusion. Note that different ischemic times (35 vs. $40 \mathrm{~min}$ ) were used to ensure adequate independent controls for every group examined.

To assess neuronal survival, hearts were exposed to $100 \mu \mathrm{M}$ nicotine for 5 min following the reperfusion period. Compounds were delivered via a syringe pump linked to an injection port immediately above the perfusion cannula. The volume of added solutions was $\leq 0.05 \%$ of the total perfusate volume. Following experimental protocols, hearts were TTC stained and imaged as previously described to quantify infarct size ${ }^{[5,28]}$.

\section{Mouse cardiomyocyte isolation}

Following avertin anesthesia, the aorta was cannulated in-situ and the heart rapidly transferred to perfusion apparatus. The heart was perfused for 3 min with a modified KrebsHenseleit "buffer A" (118 mM NaCl, 4.7 mM KCl, $1.2 \mathrm{mM} \mathrm{KH}_{2} \mathrm{PO}_{4}, 1.2 \mathrm{mM} \mathrm{MgSO}$, $10 \mathrm{mM} \mathrm{HEPES}$, $24 \mathrm{mM} \mathrm{NaHCO}_{3}, 5.5 \mathrm{mM}$ glucose, bubbled with $95 \% \mathrm{O}_{2}, 5 \% \mathrm{CO}_{2}, \mathrm{pH} 7.35,37^{\circ} \mathrm{C}$ ) at $3 \mathrm{ml} / \mathrm{min}$ to remove blood. The heart was then perfused with digestion buffer (buffer A plus $0.25 \mathrm{mM} \mathrm{CaCl}_{2}$, $30 \mathrm{mM}$ taurine, $10 \mathrm{mM}$ 2,3-butanedione monoxime, 0.0278\% Trypsin, $25 \mathrm{mg}$ collagenase A, 75 mg collagenase D) at $3 \mathrm{ml} / \mathrm{min}$ for $12 \mathrm{~min}$. The heart was removed and teased apart with forceps. Tissue was dispersed with $10 \mathrm{ml}$ stop buffer (buffer A plus $12.5 \mu \mathrm{M} \mathrm{CaCl}_{2}, 10 \% \mathrm{FBS}$ ) with a transfer pipette, then passed through a $200 \mu \mathrm{m}$ filter. Myocytes were settled by gravity for $10 \mathrm{~min}$, supernatant removed, and pellet resuspended in $10 \mathrm{ml}$ stop buffer. $\mathrm{Ca}^{2+}$ was gradually increased from $12.5 \mu \mathrm{M}$ to $0.25 \mathrm{mM}$ through four additions of $\mathrm{CaCl}_{2}$ over the course of 8 min. Myocytes were settled by gravity for $10 \mathrm{~min}$, supernatant removed, and pellet resuspended in $5 \mathrm{ml}$ normoxic buffer (buffer $\mathrm{A}$ plus $0.25 \mathrm{mM} \mathrm{CaCl}_{2}, 10 \% \mathrm{FBS}$ ). Myocytes were counted and viability determined by Trypan blue exclusion. One mouse heart typically yielded $1.2 \times 10^{6}$ cells (75\% viable) and cells were used for simulated IR injury immediately after isolation.

\section{Mouse cardiomyocyte simulated IR injury.}


Myocytes were equilibrated at a concentration of $10^{5}$ cells $/ \mathrm{ml}$ for $10 \mathrm{~min}$ in normoxic buffer. Incubations were in $50 \mathrm{ml}$ round-bottom tubes in a shaking water bath ( 80 cycles/min) at $37^{\circ} \mathrm{C}$. Myocytes were divided in to the following groups (i) Control, $100 \mathrm{~min}$ in normoxic buffer; (ii) Simulated ischemia-reperfusion (SIR), 10 min normoxic buffer, then $1 \mathrm{hr}$ ischemia buffer (118 $\mathrm{mM} \mathrm{NaCl}, 4.7 \mathrm{mM} \mathrm{KCl}, 1.2 \mathrm{mM} \mathrm{KH}_{2} \mathrm{PO}_{4}, 1.2 \mathrm{mM} \mathrm{MgSO}_{4}, 10 \mathrm{mM}$ HEPES, $24 \mathrm{mM} \mathrm{NaHCO}_{3}, 0.25$ $\mathrm{mM} \mathrm{CaCl} 2,10 \% \mathrm{FBS}$, gassed with $95 \% \mathrm{~N}_{2}, 5 \% \mathrm{CO}_{2}, \mathrm{pH} 6.5,37^{\circ} \mathrm{C}$ ), followed by 30 min normoxic buffer; (iii) Drug + SIR, comprising treatment with compounds 10 min prior to SIR in normoxic buffer, then $1 \mathrm{hr}$ ischemia buffer, 30 min normoxic buffer. Drugs tested (final concentrations in parentheses) were: NS1619 (5 $\mu \mathrm{M})$, NS11021 (500 nM) and diazoxide (10 $\mu \mathrm{M})$. Drugs were dissolved in DMSO and the vehicle comprised $<0.1 \%$ of total incubation volume. DMSO was included in the control and SIR groups at the appropriate times. To change buffers, cells were centrifuged at $31 \times \mathrm{g}$ for $2 \mathrm{~min}$, and the pellet resuspended in the appropriate buffer. At the end of protocols, viability was determined by Trypan blue exclusion.

\section{Isolated mitochondrial BK channel activity}

Mitochondria were isolated from 3 mouse hearts as previously described ${ }^{[29]}$. The mitochondria were incubated with $20 \mu \mathrm{M}$ BTC-AM and 0.05\% Pluronic F-127 for 10 min at room temperature. The final mitochondrial pellet was suspended in $225 \mu \mathrm{l}$ and stored on ice until use, within $1.5 \mathrm{hr} \mathrm{Tl}^{+}$uptake into mitochondria was measured using a Varian Cary Eclipse spectrofluorimeter as previously described ${ }^{[29]}$ by monitoring changes in BTC fluorescence $\left(\lambda_{\text {EX }}\right.$ $488 \mathrm{~nm}, \lambda_{\mathrm{EM}} 525 \mathrm{~nm}$ ). Where indicated, ATP (to block $\mathrm{mK}_{\mathrm{ATP}}$ channel), NS compounds (to open mBK channels) and paxilline (to block BK channels) were present at concentrations indicated.

\section{Total heart histochemical acetylcholinesterase staining}

Following IR protocols as described above, hearts were perfused with $10 \mathrm{mM}$ phosphate buffered saline (PBS; $\mathrm{pH} 7.4$ at $25^{\circ} \mathrm{C}$ ) for $3 \mathrm{~min}$ at $4 \mathrm{ml} / \mathrm{min}$. Control hearts not exposed to IR injury were cannulated and perfused with PBS. Hearts were then stained for acetylcholinesterase ${ }^{[30]}$. Hearts were prefixed with $4 \%$ formalin for $30 \mathrm{~min}$ at $4^{\circ} \mathrm{C}$, then washed with PBS and incubated in PBS supplemented with hyaluronidase $(0.5 \mathrm{mg} / 100 \mathrm{ml})$ for $18 \mathrm{hr}$ at 
$4^{\circ} \mathrm{C}$. The hearts were then placed in Karnovsky-Roots medium (60 mM sodium acetate, $2 \mathrm{mM}$ acetylthiocholine iodide, $15 \mathrm{mM}$ sodium citrate, $3 \mathrm{mM} \mathrm{CuSO}_{4}, 0.5 \mathrm{mM} \mathrm{K}_{3} \mathrm{Fe}(\mathrm{CN})_{6}, 0.1 \%$ trition-X $100,0.5 \mathrm{mg} / 100 \mathrm{ml}$ hyaluronidase, $\mathrm{pH} 5.6$ at $4^{\circ} \mathrm{C}$ ) for $3 \mathrm{hr}$ at $4^{\circ} \mathrm{C}$. Following staining, hearts were kept in $10 \%$ formalin and visualized under fluorescent illumination using GFP filters on an Olympus MVX wide field dissecting microscope. Images were obtained using a PixeLink camera. The fluorescent illumination provided increased contrast compared to visible light with the monochrome CCD.

\section{Statistics}

Data presented are means \pm SEM. Statistical significance $(p<0.05)$ between multiple groups was determined using analysis of variance (ANOVA) with Bonferroni correction. Mixed effects models were generated using " $R$ " software (R Development Core Team) and the R packages Ime4 ${ }^{[31]}$ and language ${ }^{[32,33]}$. As fixed effects, we included treatment conditions, genotype, and their interaction in the model. Normality and homogeneity were checked using visual inspections of plots of residuals against fitted values. Likelihood ratio tests comparing the models with fixed effects to the null models using only random effects, were used to assess the accuracy of the mixed effects models. The model was further analyzed using pair wise comparison t-test. We rejected results where the model including fixed effects did not differ significantly from the null model. For all mixed effects models we present MCMC-estimated pvalues that are considered significant at the $\alpha<0.05$ level.

\section{RESULTS}

\section{Protection of intact hearts by NS1619 and NS11021 requires Slo1}

Previously we showed that cardioprotection by both IPC and APC in intact hearts is SLO1 independent ${ }^{[5]}$. However, the SLO1 openers NS1619 and NS11021 are still reported to protect against IR injury in intact hearts ${ }^{[4,11]}$, suggesting that SLO1 alone can afford protection. To examine the pharmaco-genomics of SLO1, NS1619 and NS11021 in more detail, we utilized an ex-vivo perfused heart model of IR injury. Representative raw data tracings of cardiac function during IR injury are shown in Figure 1. Hearts from WT and $S / 01^{-1-}$ mice exhibited similar 
sensitivity to IR (quantitative data shown in Figure 2), and as previously reported both NS1619 and NS11021 protected the WT heart from IR injury (enhanced functional recovery and reduced infarct size), with NS11021 being 10-fold more potent than NS1619. As anticipated, protection was lost in $\mathrm{Slo1}^{-/-}$hearts, suggesting that SLO1 is a bona-fide target for the cardioprotective effects of NS1619 and NS11021 in the intact heart. While it is possible that SLO1 is merely a downstream mediator of protection by NS1619 and NS11021, Occam's razor would suggest SLO1 is the actual target.

\section{Protection of isolated cardiomyocytes by NS1619 and NS11021 is Slo1 independent}

Slo1 mRNA is expressed at low levels in whole heart ${ }^{[8-10]}$, and it has been suggested that SLO1 is present in cardiomyocyte mitochondria ${ }^{[11]}$. We therefore hypothesized that SLO1 in cardiomyocyte mitochondria may play a role in mediating the protective effects of NS1619 and NS11021. To test this hypothesis, adult mouse ventricular cardiomyocytes were isolated from WT and Slo $1^{--}$hearts and subjected to simulated IR injury. As expected, both NS1619 and NS11021 elicited cytoprotection (reduced cell death) in response to IR (Figure 3). However, this protection was present in both WT and Slo $1^{\%}$ derived myocytes, indicating it did not require SLO1 activity. As a control, the mitochondrial $\mathrm{K}_{\text {ATP }}$ opener diazoxide was protective in both WT and $S / O 1^{-/-}$cells. Overall these data suggest that the protection of cardiomyocytes by NS1619 and NS11021 may be due to off-target (non-SLO1) effects of these molecules, as reported elsewhere $^{[16-23]}$.

\section{NS1619 and NS11021 exhibit Slo1 independent effects on isolated mitochondria}

To directly test whether NS1619 and NS11021 were able to activate BK channels in isolated mitochondria, a modified thallium $\left(\mathrm{Tl}^{+}\right)$flux assay was utilized ${ }^{[29]}$. As expected, both compounds were able to elicit a $\mathrm{TI}^{+}$flux, in a manner sensitive to the BK channel blocker paxilline (Figure 4). However, this flux was evident in mitochondria derived from both WT and $\mathrm{SlO}^{-/-}$hearts, indicating it did not originate at the level of SLO1. Furthermore, bona fide mitochondrial $\mathrm{K}^{+}$channels exhibit a slowing of $\mathrm{Tl}^{+}$flux kinetics by increasing concentrations of $\mathrm{K}^{+}$ and not $\mathrm{Na}^{+}$(since only $\mathrm{K}^{+}$competes for $\mathrm{Tl}^{+}$uptake). However, such competition was not seen 
for NS induced $\mathrm{Tl}^{+}$flux (data not shown), suggesting it is not ion-specific. Together these data support the notion that NS compounds have non-specific effects on mitochondria. Such effects may account for the non Slo1-dependent protection observed in isolated cardiomyocytes (Figure 3).

\section{SLO1 dependent protection in intact hearts requires cardiac neuronal function}

So far, our data show that SLO1 is not required for protection by NS1619 and NS11021 in isolated cardiomyocytes (Figure 3), but is required for protection by these compounds in the intact heart (Figures $1 \& 2$ ). This suggests that in the intact heart, protection occurs via SLO1 in a mechanism that is non-cardiomyocyte autonomous. Several non-myocyte cardioprotective mechanisms exist, including remote preconditioning which is thought to comprise a neuronal signaling component ${ }^{[34]}$. We therefore sought to investigate a role for SLO1 in cardioprotection via non myocyte signaling, with a focus on intrinsic cardiac neurons. Importantly, the ex-vivo heart preparation used herein is denervated, such that surviving neurons are not central but rather they are intrinsic to the heart. In addition SLO1 channel activity has been described in cardiac neurons $^{[13]}$ and Purkinje fibers ${ }^{[14]}$, where it plays a role in regulating heart rate ${ }^{[5,15]}$.

Figure 5 shows that blockade of neuronal function with the synaptic transmission inhibitor hexamethonium, prevented cardioprotection (reduction in infarct size) by NS1619 in intact hearts. This effect was specific to SLO1 and NS1619, since hexamethonium had no effect

on protection afforded by the mitochondrial $\mathrm{K}_{\text {ATP }}$ channel activator atpenin $A 5^{[35]}$. These data also indicate that NS1619 protects via a mechanism that is distinct from mitochondrial $\mathrm{K}_{\text {ATP }}$ channel opening.

To further investigate the role of cardiac neurons in protection afforded by SLO1 activators, we assessed neuronal status by histochemical staining for acetylcholinesterase activity (AChE). No differences in AChE staining were found between control, IR, and IR + NS1619 hearts, suggesting the acute time frame of IR injury in this model was not sufficient to precipitate neuronal loss (Figure $6 \mathrm{~A} / \mathrm{B} / \mathrm{C}$ ). We therefore hypothesized that a more direct test of cardiac neuronal function might be necessary to assess neuronal protection in this acute model. Hence, the response of heart rate to nicotine (which induces transient tachycardia via nicotinic 
Ach receptors ${ }^{[36,37]}$ ) was measured after IR injury. As seen in Figure 6D, no response to nicotine was seen in control hearts subjected to IR, indicating loss of neuronal function. However, hearts protected with NS1619 exhibited a robust post-IR nicotine response, and this effect was blocked by pre-treatment with hexamethonium, indicating a preservation of nicotine-sensitive intrinsic cardiac neurons. Notably, hearts protected with the $\mathrm{mK}_{\text {ATP }}$ opener atpenin $\mathrm{A} 5$ did not exhibit a preserved nicotine response. This is consistent with the data in Figure 4 showing that even though atpenin A5 was protective, this cardioprotection was insensitive to hexamethonium. Overall these data indicate that both $\mathrm{mK}_{\text {ATP }}$ and SLO1 channels can protect the heart (Figures 1, $2 \& 5)$, but they do so via distinct mechanisms, the latter requiring cardiac neuron function.

\section{DISCUSSION}

Together, the current data suggest that the SLO1 openers NS1619 and NS11021 act to preserve intrinsic cardiac neuronal function in IR injury, in a Slo1 dependent manner, and this leads to protection of myocardium. As such, the function of cardiomyocytes in IR injury can be preserved by activation of a non-cardiomyocyte-autonomous signaling mechanism. From a pharmaco-genomic perspective, this is the first study to show that cardioprotection in the intact heart by the putative SLO1 activators NS1619 and NS11021 actually requires the Slo1 gene product (Figures $1 \& 2$ ).

Although the chemical structures of NS1619 and NS11021 are quite diverse, an inactive analog of NS11021 (NS13558) does not elicit cardioprotection ${ }^{[38]}$, suggesting these molecules bind to a specific target in the whole heart, presumably SLO1. While the mitochondrial $\mathrm{K}_{\mathrm{ATP}}$ channel would appear to be an obvious alternative target for the NS compounds, protection by NS1619 is not blocked by the $\mathrm{mK}_{\text {ATP }}$ blocker $5-\mathrm{HD}^{[39]}$, suggesting this is not the case. Rather, the mechanism of protection by SLO1 openers is distinct from that afforded by activation of cardiac $\mathrm{mK}_{\text {ATP }}$ channels (e.g., by diazoxide or atpenin A5), and suggests that non-myocyte and possibly non-mitochondrial $\mathrm{K}^{+}$channels are also important in determining responses to ischemia.

The data in Figures 5 and 6 suggest that cardioprotection by SLO1 activators proceeds via intrinsic cardiac neurons, with preservation of neuronal function during IR injury leading to improved cardiac functional recovery, decreased infarct size (Figure 5), and the post-IR ability to 
mount a tachycardic response to nicotine (Figure 6D). This nicotine response requires both intact cardiac neurons and the ability of myocytes to respond to a tachycardic signal. Notably, hearts protected by $\mathrm{mK}_{\mathrm{ATP}}$ agonist atpenin $\mathrm{A} 5$ were fully competent at the contractile level postIR (Figure 5), but failed to respond to nicotine. This suggests a post-IR defect in a noncardiomyocyte cell-type, presumably neurons since this is the only other cell type known to be involved in the nicotine response. Post-IR in NS1619 treated hearts responded to nicotine in a manner that was blocked by hexamethonium (Figure 6D), and the preservation of contractile function by NS1619 was also blocked by hexamethonium (Figure 5).

Overall, the most logical explanation for these data is that NS1619 protection proceeds via SLO1 in cardiac neurons. However, we cannot rule out the possibility that NS1619 acts on other neuronal targets. Unfortunately this cannot be tested experimentally using $S / o 1^{-/-}$mice, because post-IR Slo1 ${ }^{-1}$ hearts treated with NS1619 are incompetent at the contractile level (Figures $1 \& 2$ ), so they cannot respond to nicotine anyway, regardless of their neuronal status. Clearly, cardiomyocyte- or neuron-specific Slo $1^{-/}$animals would be of enormous benefit in further elucidating the protective mechanism of the NS compounds in future.

While a role for afferent or efferent neurons (or indeed residual synaptic bulbs from central neurons) cannot be completely ruled out ${ }^{[40]}$, it should be emphasized that the Langendorff perfused heart preparation is denervated upon removal of the heart from the thorax, and thus the neurons of interest to this study are not afferent or efferent to the central system, but are intrinsic to the heart. The presence of ganglionated plexuses within the heart is well documented ${ }^{[41]}$, and a number of important signaling roles have been assigned to such neurons, including cardiac responses to nitric oxide ${ }^{[42]}$, endothelin ${ }^{[43]}$, histamine [44], angiotensin $\mathrm{II}^{[45]}, \alpha / \beta$ adrenergic agonists ${ }^{[46]}$, and nicotine ${ }^{[47]}$. Although the intrinsic cardiac neuronal system has been proposed to play a role in cardiac responses to ischemia ${ }^{[48]}$, the current study is among the first to directly demonstrate this concept.

The activity of intrinsic cardiac neurons is increased during ischemia ${ }^{[49]}$. Furthermore, SLO1 in neurons regulates neurotransmitter release ${ }^{[50]}$, and the loss of SLO1 results in an increased duration of release ${ }^{[50]}$. Thus, activating SLO1 with NS1619 or NS11021 may hyperpolarize neurons, limiting neurotransmitter release and minimizing the neuronal 
depolarization and excitotoxicity associated with ischemic events ${ }^{[51]}$. In simple terms, the NS compounds may prevent excitotoxicity. The ability to modulate cardiac neuronal activity in this manner is a promising therapeutic avenue for ischemic injury ${ }^{[52]}$. Recently, several non-myocyte cell types in the heart have emerged as key players in the response to ischemic injury, including cardiac fibroblasts ${ }^{[53]}$, cardiac mast cells ${ }^{[54,55]}$, and cardiac stem/progenitor cells ${ }^{[56]}$. At this stage, it is not clear whether the cardioprotection observed herein represents a direct effect of cardiac neurons on cardiomyocytes, and the potential involvement of additional intermediary cell types in transmitting the protective signal cannot be excluded.

The precise sub-cellular location of SLO1 required for protection by NS1619 and NS11021 remains unclear. Early work on the role of SLO1 in cardioprotection found no expression on the surface of cardiomyocytes ${ }^{[11]}$. When single-channel recordings of a $\mathrm{Ca}^{2+}$ dependent $\mathrm{K}^{+}$channel were made in human glioma cell mitochondria ${ }^{[7]}$ a consensus emerged that the cardioprotective effect of SLO1 activators was likely due to a SLO1 channel in cardiomyocyte mitochondria ${ }^{[11]}$. Observations that the SLO channel blocker paxilline abrogates protection by NS1619 and NS11021 ${ }^{[4,11]}$, as well as the protection afforded by APC ${ }^{[5]}$, are often invoked as proof for the existence of a "cardiac mitochondrial $\mathrm{K}_{\mathrm{Ca}}$ channel", and this naming convention is consistent with the fact that mammalian SLO1 is a $\mathrm{Ca}^{2+}$ sensitive isoform of SLO ${ }^{[6]}$. Further support comes from immunological studies, in which antibodies directed against the canonical SLO1 (110-130 kDa) detect the protein in mitochondrial fractions $(120,80$, and 55 kDa) ${ }^{[11,57-59]}$.

More recently however, the consensus view that SLO1 is a mitochondrial $\mathrm{K}_{\mathrm{Ca}}$ channel important for cardioprotection has been challenged by our observation that SLO1 is dispensable for APC and IPC ${ }^{[5]}$. Furthermore, although the SLO auxiliary subunit $\beta 4^{[57,60-62]}$ has been found in mitochondria, this subunit renders SLO1 resistant to charybdotoxin and iberiotoxin - toxins that block the effects of NS1619 on mitochondria ${ }^{[63]}$. We have also shown that in the model organism C. elegans, the SLO2 isoform of the channel underlies both APC and mitochondrial $\mathrm{K}^{+}$ flux ${ }^{[5]}$. While studies are ongoing to confirm the identity of the mitochondrial BK channel, it seems clear that the simple picture of a SLO1 channel in cardiomyocyte mitochondria as the underlying mechanism of cardioprotection by APC or NS compounds is untenable. Indeed, the 
data in Figure 3 show that NS compounds elicited $\mathrm{K}^{+}$transport in isolated mitochondria independent of SLO1, adding to the body of evidence for off-target effects of these compounds at the mitochondrial level.

Subsequently, the question arises as to the mechanism by which the SLO1 openers NS1619 and NS11021 can elicit protection in isolated cardiomyocytes ${ }^{[57,64]}$, in a Slo1 independent manner (Figure 3). It seems reasonable to suggest that the well-documented offtarget effects of these molecules (reinforced by data in Figure 4) may underlie such protection ${ }^{[19,21-23]}$. Both NS1619 and NS11021 have been reported to inhibit respiration ${ }^{[21,23]}$, promote mitochondrial depolarization ${ }^{[20-23]}$ and cause mitochondrial swelling independent of $\mathrm{K}^{+}{ }^{[21,65]}$ suggesting they can impact non-specific ion transport mechanisms ${ }^{[19,21]}$. NS1619 has also been shown to increase mitochondrial ROS generation without depolarization ${ }^{[66]}$, and a role for small amounts of ROS in cardioprotective signaling is well known ${ }^{[67]}$. Alternatively, NS1619 and NS11021 may protect cardiomyocytes via non-mitochondrial targets that remain to be identified.

Mitochondrial ion channels such as the $\mathrm{mK}_{\mathrm{ATP}}$ and SLO2 remain important mediators of IPC and APC cardioprotective signaling ${ }^{[1,5,68-70]}$, and it should be emphasized that the data presented herein do not preclude the presence of a SLO1 channel in the mitochondria. Slo1 has many splice variants ${ }^{[6]}$ and it is possible that such variants may be present in the mitochondrion, but these channels are either not the primary target or lack the binding site necessary to respond to NS1619 and NS11021. Furthermore, the Slo $1^{--}$mouse used in these studies has a deletion of Exon 1, which encodes the So domain required for channel function ${ }^{[24-26]}$, making it unlikely that a functional splice variant is present in the knockout. Further studies are needed to determine the nature of any SLO1 in mitochondria, or to investigate the intriguing notion that SLO1 may reside in the mitochondria of intrinsic cardiac neurons.

A surprising paradox emerges when comparing the whole heart and cardiomyocyte effects of NS1619 and NS11021 (Figures 2 \& 3). Specifically, if these compounds are capable of protecting isolated cardiomyocytes in a Slo1 independent manner, why is this mechanism of protection not accessible in whole hearts? If it were, the compounds should protect the S/o $1^{-/-}$ heart. One possibility may be the different experimental systems, or that the isolated myocytes 
does not express SLO1, which may promote nonspecific actions of these compounds. Another possibility is that a barrier exists in the intact heart (possibly a vascular diffusional barrier) which prevents NS1619 and NS11021 from activating the protective pathway observed in cells. Notably, attempts to overcome this limitation by using high concentrations of NS1619 (30 $\mu \mathrm{M})$ in the intact heart led to an exacerbation of IR injury (data not shown), which may be related to reports that high concentrations of this compound can depolarize mitochondria ${ }^{[21]}$. Notably, a recent review article stated that "In whole heart experiments the effective concentration of NS1619 is actually lower due to limited diffusion of the drug to its site of action, and thus, it promotes cardioprotection instead of mitochondrial damage and heart stress." [59]

Clearly in the intact heart, something prevents NS1619 and NS11021 from protecting myocytes directly, such that the only avenue of protection available to these molecules is via SLO1, and knocking out the channel abrogates this protective mechanism. A schematic outlining the different actions of NS1619 and NS11021 in isolated myocytes vs. intact hearts is shown in Figure 6 , with the exact nature of the protective signal initiated at the cardiac neuronal level by SLO1 openers still to be elucidated.

In conclusion, the SLO1 channel is a cardioprotective target of NS1619 and NS11021, and these molecules are important tools for assessing SLO1 function in the whole heart. The molecules elicit protection in isolated cardiomyocytes that is independent of SLO1, possibly mediated by off-target effects. In contrast at the whole heart level, protection by NS1619 and NS11021 absolutely requires SLO1, and preserves intrinsic cardiac neuronal function. Collectively these studies support the notion that intrinsic cardiac neurons are important mediators of cardioprotection, and may be a therapeutic target ${ }^{[71]}$.

\section{ACKNOWLEDGEMENTS}

We thank James Melvin (NIH) and Richard Aldrich (University of Texas at Austin) for the $\mathrm{SlO}^{-/-}$mice. This work was funded by grants from the US National Institutes of Health to PSB (RO1-HL071158), PSB \& KWN (RO1-GM-087483) and an American Heart Association, Founder Affiliate Postdoctoral Fellowship award to APW (11POST7290028). 


\section{DISCLOSURES}

Morten Grunnet is a former employee of Neurosearch Inc., which supplied NS11021. 


\section{FIGURE LEGENDS}

Figure 1. Representative left ventricular pressure traces from perfused hearts. Traces are shown for wild-type (WT) and S/o1\% hearts, in the presence of vehicle (Ctrl.), NS1619 or NS11021, as per the methods. Traces are compressed on the time $(x)$ axis. The top and bottom boundaries of the black shaded area represent the systolic and diastolic pressures, respectively. The onset of ischemia (I) and reperfusion (R) are indicated by arrows. Scale bars on each trace represent $10 \mathrm{~min}$. (x-axis) and $50 \mathrm{mmHg}$ (y-axis).

Figure 2. SLO1 dependent protection of perfused mouse heart against ischemia-reperfusion (IR) injury. Perfused FVB littermate WT (white symbols) and S/o1 ${ }^{-/-}$(gray symbols) mouse hearts were subjected to IR injury. Where indicated, hearts were treated with NS1619 (5 $\mu \mathrm{M}$ ) or NS11021 (500 nM) prior to ischemia. (A): Left-ventricular function was determined as rate pressure product (RPP; heart rate $\mathrm{x}$ left ventricular developed pressure) and expressed as percent of initial value. Statistical significance between groups was determined using a mixedeffects model. ${ }^{*} p<0.05$ between NS11021 and control (IR alone), $\# p<0.05$ between NS1619 and control (IR alone). (B): Following IR protocols, hearts were sliced, stained with TTC and fixed to delineate live (red) from dead or infarcted tissue (white). Infarcts were quantified by planimetry and expressed as a percent of the area at risk (100\% in this global ischemia model). Images above the graph show representative slices from each group. Within each group, individual values are on the left, and means \pm SEM on the right $(N=7$ for IR group and 6 for all other groups). ${ }^{*} p<0.05$ between NS11021 and control (IR alone), \#p<0.05 between NS1619 and control (IR alone).

Figure 3. SLO1 independent protection of adult mouse cardiomyocytes against simulated ischemia-reperfusion (IR) injury. Myocytes were isolated from adult littermate WT (white) and $\mathrm{SlO1}^{-/-}$(gray) mouse hearts, and used immediately in the model of IR injury. Where indicated, cells were treated with NS1619 (5 $\mu \mathrm{M})$, NS11021 (500 nM) or diazoxide (DZX, $10 \mu \mathrm{M})$. Upon completion of the IR protocol, cell viability was measured via Trypan blue exclusion and expressed as a percent of control (viability in control normoxic groups was: WT $70 \pm 3 \%$, Slo $1^{-/-}$ 
$69 \pm 4 \%)$. Experimental conditions are listed below the $\mathrm{x}$-axis. Data are means $\pm \mathrm{SEM}$, with $\mathrm{N}$ for each group listed in parentheses at the base off each bar. Each $\mathrm{N}$ represents an independent cardiomyocyte preparation. ${ }^{*} p<0.05$ vs. IR alone (ANOVA).

Figure 4: SLO1 independent $\mathrm{K}^{+}$channel activity in isolated mouse heart mitochondria. Mitochondria were isolated from littermate WT (white) and Slo $1^{-/}$(gray) mouse hearts and loaded with $\mathrm{Tl}^{+}$-sensitive fluorophore. Mitochondrial $\mathrm{K}^{+}$channel activity in the presence of NS compounds was determined using the $\mathrm{TI}^{+}$-flux assay. Data are presented as $\Delta$ fluorescence upon $\mathrm{Tl}^{+}$addition to media. ATP was present to block the $\mathrm{mK}_{\text {ATP }}$ channel. The baseline $\Delta$ fluorescence (Ctrl, set to $100 \%$ ) was $24.7 \pm 2.3$ and $24.9 \pm 4.4$ arbitrary units in WT (white bars) and Slo1\% (gray bars), respectively. Experimental conditions are listed below the $x$-axis. Data are means \pm SEM, with $\mathrm{N}$ for each group listed in parentheses at the base off each bar. Each $\mathrm{N}$ represents an independent mitochondrial preparation. Control, ATP and ATP + Pax data are replicated between panels $A$ and $B$ for comparison $* p<0.05$ vs. ATP, $+p<0.05$ vs. ATP + NS compound (ANOVA).

Figure 5. Blocking cardiac neuronal function blocks SLO1 dependent protection in the intact heart. (A/B): Perfused FVB mouse hearts from WT animals were subjected to IR injury. Where indicated, hearts were treated with NS1619 $(5 \mu \mathrm{M})$, atpenin A5 (AA5, $10 \mathrm{nM})$, or hexamethonium (Hex, $500 \mu \mathrm{M}$ ) as detailed in the methods. Left-ventricular function was determined as rate pressure product (RPP; heart rate $\mathrm{x}$ left ventricular developed pressure) and expressed as a percent of initial value. Data are split across two panels for clarity. Statistical significance between groups was determined using a mixed-effects model. ${ }^{*} p<0.05$ vs. IR alone, $\#$ p $<0.05$ vs. NS1619 + IR. (C): Following IR protocols, hearts were sliced, stained with TTC and fixed to delineate live (red) from dead or infarcted tissue (white). Infarcts were quantified by planimetry and expressed as a percent of the area at risk (100\% in this global ischemia model). Images above the graph show representative slices from each group. Within each group, individual values are on the left, and means \pm SEM on the right $(\mathrm{N}=8$ for IR, 7 for $A A 5+I R$, and 6 for all other groups). ${ }^{*} p<0.05$ vs. IR alone, $\# p<0.05$ vs. NS1619+IR. 
Figure 6. Histochemical staining and functional activity of cardiac neurons. Perfused FVB mouse hearts from WT animals were subjected to IR injury. Where indicated, hearts were treated with NS1619 $(5 \mu \mathrm{M})$, atpenin A5 (AA5, $10 \mathrm{nM})$, hexamethonium (Hex, $500 \mu \mathrm{M})$, or combinations of NS1619 + Hex or AA5 + Hex, as detailed in the methods. Panels A-C show representative total heart histochemical acetylcholinesterase (AChE) staining following (A) control perfusion, (B) IR injury and (C) IR with NS1619 pre-treatment. Dorsal side of the heart is shown, with magnifications of boxed areas shown in right panels. (D): Functional activity of cardiac neurons was determined following the six IR protocols used in Figure 3, via the injection of nicotine $(100 \mu \mathrm{M})$ for $5 \mathrm{~min}$. The peak heart rate increase was found at $2 \mathrm{~min}$., followed by desensitization and subsequent decrease in heart rate. Data are means \pm SEM. $\mathrm{N}$ for each group is shown in parentheses to the right of the legend. Each $\mathrm{N}$ represents an individual perfused heart. $* p<0.05$ vs. IR (ANOVA).

Figure 7. Working model of SLO1 (in)dependent mechanisms of action in NS1619/NS11021 cardioprotection. (A): In isolated cardiomyocytes the NS compounds induce cardioprotection independent of SLO1. The 'target' remains unclear but may include inhibition of respiration or the uncoupling of oxidative phosphorylation (see text for details). This mechanism is compatible with the lack of evidence for SLO1 in cardiomyocytes. (B): In the whole heart, cardioprotection by NS1619/NS11021 is dependent on SLO1 and is likely mediated via a cell non-autonomous mechanism, involving intrinsic cardiac neurons. A barrier is hypothesized to exist, possibly accounting for the inability of NS compounds to recruit the nonspecific target responsible for protection in myocytes. This explains the lack of ability of NS1619/NS11021 to protect the intact Slo $1^{-/-}$heart. HEX = hexamethonium. 


\section{REFERENCES}

1. Facundo $\mathrm{HT}$, Fornazari $\mathrm{M}$, Kowaltowski AJ. Tissue protection mediated by mitochondrial $\mathrm{K}^{+}$ channels. Biochim Biophys Acta 2006; 1762: 202-12.

2. O'Rourke B. Mitochondrial ion channels. Annu Rev Physiol 2007; 69: 19-49.

3. Zoratti M, De MU, Gulbins E, Szabo I. Novel channels of the inner mitochondrial membrane. Biochim Biophys Acta 2009; 1787: 351-63.

4. Bentzen BH, Osadchii O, Jespersen T, Hansen RS, Olesen SP, Grunnet M. Activation of big conductance $\mathrm{Ca}^{2+}$-activated $\mathrm{K}^{+}$channels (BK) protects the heart against ischemiareperfusion injury. Pflugers Arch 2009; 457: 979-88.

5. Wojtovich AP, Sherman TA, Nadtochiy SM, Urciuoli WR, Brookes PS, Nehrke K. SLO-2 Is Cytoprotective and Contributes to Mitochondrial Potassium Transport. PLoS One 2011; 6: e28287.

6. Salkoff L, Butler A, Ferreira G, Santi C, Wei A. High-conductance potassium channels of the SLO family. Nat Rev Neurosci 2006; 7: 921-31.

7. Siemen D, Loupatatzis C, Borecky J, Gulbins E, Lang F. Ca ${ }^{2+}$-activated K channel of the BKtype in the inner mitochondrial membrane of a human glioma cell line. Biochem Biophys Res Commun 1999; 257: 549-54.

8. Chen L, Tian L, MacDonald SH, McClafferty H, Hammond MS, Huibant JM, et al. Functionally diverse complement of large conductance calcium- and voltage-activated potassium channel (BK) alpha-subunits generated from a single site of splicing. J Biol Chem 2005; 280: 33599-609.

9. Jiang Z, Wallner M, Meera P, Toro L. Human and rodent MaxiK channel beta-subunit genes: cloning and characterization. Genomics 1999; 55: 57-67.

10. Tseng-Crank J, Foster CD, Krause JD, Mertz R, Godinot N, DiChiara TJ, et al. Cloning, expression, and distribution of functionally distinct $\mathrm{Ca}^{2+}$-activated $\mathrm{K}^{+}$channel isoforms from human brain. Neuron 1994; 13: 1315-30.

11. Xu W, Liu Y, Wang S, McDonald T, Van Eyk JE, Sidor A, et al. Cytoprotective role of $\mathrm{Ca}^{2}+-$ activated $\mathrm{K}^{+}$channels in the cardiac inner mitochondrial membrane. Science 2002; 298: 1029-33. 
12. Bentzen BH, Nardi A, Calloe K, Madsen LS, Olesen SP, Grunnet M. The small molecule NS11021 is a potent and specific activator of $\mathrm{Ca}^{2+}$-activated big-conductance $\mathrm{K}^{+}$channels. Mol Pharmacol 2007; 72: 1033-44.

13. Franciolini F, Hogg R, Catacuzzeno L, Petris A, Trequattrini C, Adams DJ. Large-conductance calcium-activated potassium channels in neonatal rat intracardiac ganglion neurons. Pflugers Arch 2001; 441: 629-38.

14. Callewaert G, Vereecke J, Carmeliet E. Existence of a calcium-dependent potassium channel in the membrane of cow cardiac Purkinje cells. Pflugers Arch 1986; 406: 424-6.

15. Imlach WL, Finch SC, Miller JH, Meredith AL, Dalziel JE. A role for BK channels in heart rate regulation in rodents. PLoS One 2010; 5: e8698.

16. Park WS, Kang SH, Son YK, Kim N, Ko JH, Kim HK, et al. The mitochondrial $\mathrm{Ca}^{2+}$-activated $\mathrm{K}^{+}$ channel activator, NS 1619 inhibits L-type Ca2+ channels in rat ventricular myocytes. Biochem Biophys Res Commun 2007; 362: 31-6.

17. Saleh SN, Angermann JE, Sones WR, Leblanc N, Greenwood IA. Stimulation of $\mathrm{Ca}^{2+}$-gated $\mathrm{Cl}$ - currents by the calcium-dependent $\mathrm{K}^{+}$channel modulators NS1619 [1,3-dihydro-1-[2hydroxy-5-(trifluoromethyl)phenyl]-5-(trifluoromethyl)-2 H-benzimidazol-2-one] and isopimaric acid. J Pharmacol Exp Ther 2007; 321: 1075-84.

18. Holland M, Langton PD, Standen NB, Boyle JP. Effects of the BK $\mathrm{Ca}_{\text {a }}$ channel activator, NS1619, on rat cerebral artery smooth muscle. Br J Pharmacol 1996; 117: 119-29.

19. Aldakkak M, Stowe DF, Cheng $Q$, Kwok WM, Camara AK. Mitochondrial matrix $\mathrm{K}^{+}$flux independent of large-conductance $\mathrm{Ca}^{2+}$-activated $\mathrm{K}^{+}$channel opening. Am J Physiol Cell Physiol 2010; 298: C530-C541.

20. Aon MA, Cortassa S, Wei AC, Grunnet M, O'Rourke B. Energetic performance is improved by specific activation of $\mathrm{K}^{+}$fluxes through $\mathrm{K}_{\mathrm{Ca}}$ channels in heart mitochondria. Biochim Biophys Acta 2010; 1797: 71-80.

21. Cancherini DV, Queliconi BB, Kowaltowski AJ. Pharmacological and physiological stimuli do not promote $\mathrm{Ca}^{2+}$-sensitive $\mathrm{K}^{+}$channel activity in isolated heart mitochondria. Cardiovasc Res 2007; 73: 720-8. 
22. Debska G, Kicinska A, Dobrucki J, Dworakowska B, Nurowska E, Skalska J, et al. Largeconductance $\mathrm{K}^{+}$channel openers NS1619 and NS004 as inhibitors of mitochondrial function in glioma cells. Biochem Pharmacol 2003; 65: 1827-34.

23. Kicinska A, Szewczyk A. Large-Conductance Potassium Cation Channel Opener NS1619 Inhibits Cardiac Mitochondria Respiratory Chain. Toxicol Mech Methods 2004; 14: 59-61.

24. Meredith AL, Thorneloe KS, Werner ME, Nelson MT, Aldrich RW. Overactive bladder and incontinence in the absence of the $\mathrm{BK}$ large conductance $\mathrm{Ca}^{2+}$-activated $\mathrm{K}^{+}$channel. $\mathrm{J} \mathrm{Biol}$ Chem 2004; 279: 36746-52.

25. Zarei MM, Zhu N, Alioua A, Eghbali M, Stefani E, Toro L. A novel MaxiK splice variant exhibits dominant-negative properties for surface expression. J Biol Chem 2001; 276: 16232-9.

26. Zarei MM, Eghbali M, Alioua A, Song M, Knaus HG, Stefani E, et al. An endoplasmic reticulum trafficking signal prevents surface expression of a voltage- and $\mathrm{Ca}^{2+}$-activated $\mathrm{K}^{+}$ channel splice variant. Proc Natl Acad Sci U S A 2004; 101: 10072-7.

27. Nadtochiy SM, Burwell LS, Ingraham CA, Spencer CM, Friedman AE, Pinkert CA, et al. In vivo cardioprotection by S-nitroso-2-mercaptopropionyl glycine. J Mol Cell Cardiol 2009; 46: 960-8.

28. Nadtochiy SM, Redman E, Rahman I, Brookes PS. Lysine deacetylation in ischaemic preconditioning: the role of SIRT1. Cardiovasc Res 2011; 89: 643-9.

29. Wojtovich AP, Williams DM, Karcz MK, Lopes CM, Gray DA, Nehrke KW, et al. A Novel Mitochondrial KATP Channel Assay. Circ Res 2010; 106: 1190-6.

30. Rysevaite K, Saburkina I, Pauziene N, Noujaim SF, Jalife J, Pauza DH. Morphologic pattern of the intrinsic ganglionated nerve plexus in mouse heart. Heart Rhythm 2011; 8: 448-54.

31. Bates D, \& Maechler M. Ime4: Linear mixed-effects models using S4 classes. R package version 0.999375-32. 2009.

32. Baayen RH. Analyzing Linguistic Data: A Practical Introduction to Statistics Using R. Cambridge: Cambridge University Press. 2008.

33. Baayen RH. languageR: Data sets and functions with "Analyzing Linguistic Data: A practical introduction to statistics". R package version 0.955. 2009. 
34. Hausenloy DJ, Yellon DM. Remote ischaemic preconditioning: underlying mechanisms and clinical application. Cardiovasc Res 2008; 79: 377-86.

35. Wojtovich AP, Brookes PS. The complex II inhibitor atpenin A5 protects against cardiac ischemia-reperfusion injury via activation of mitochondrial $\mathrm{K}_{\text {ATP }}$ channels. Basic Res Cardiol 2009; 104: 121-9.

36. Tosaka $\mathrm{T}$, Casimiro MC, Rong $\mathrm{Q}$, Tella $\mathrm{S}$, Oh M, Katchman AN, et al. Nicotine induces a long QT phenotype in Kcnq1-deficient mouse hearts. J Pharmacol Exp Ther 2003; 306: 980-7.

37. Haass M, Kubler W. Nicotine and sympathetic neurotransmission. Cardiovasc Drugs Ther 1997; 10: 657-65.

38. Bentzen BH, Andersen RW, Olesen SP, Grunnet M, Nardi A. Synthesis and characterisation of NS13558: a new important tool for addressing $\mathrm{K}_{\mathrm{Ca}} 1.1$ channel function ex vivo. Naunyn Schmiedebergs Arch Pharmacol 2010; 381: 271-83.

39. Cao CM, Xia Q, Gao Q, Chen M, Wong TM. Calcium-activated potassium channel triggers cardioprotection of ischemic preconditioning. J Pharmacol Exp Ther 2005; 312: 644-50.

40. Wenk HN, McCleskey EW. A novel mouse skeletal muscle-nerve preparation and in vitro model of ischemia. J Neurosci Methods 2007; 159: 244-51.

41. Yuan BX, Ardell JL, Hopkins DA, Losier AM, Armour JA. Gross and microscopic anatomy of the canine intrinsic cardiac nervous system. Anat Rec 1994; 239: 75-87.

42. Armour JA, Smith FM, Losier AM, Ellenberger HH, Hopkins DA. Modulation of intrinsic cardiac neuronal activity by nitric oxide donors induces cardiodynamic changes. Am J Physiol 1995; 268: R403-R413.

43. Armour JA. Comparative effects of endothelin and neurotensin on intrinsic cardiac neurons in situ. Peptides 1996; 17: 1047-52.

44. Armour JA. Histamine-sensitive intrinsic cardiac and intrathoracic extracardiac neurons influence cardiodynamics. Am J Physiol 1996; 270: R906-R913.

45. Horackova M, Armour JA. ANG II modifies cardiomyocyte function via extracardiac and intracardiac neurons: in situ and in vitro studies. Am J Physiol 1997; 272: R766-R775.

46. Armour JA. Intrinsic cardiac neurons involved in cardiac regulation possess alpha 1-, alpha 2-, beta 1- and beta 2-adrenoceptors. Can J Cardiol 1997; 13: 277-84. 
47. Murphy DA, O'Blenes S, Hanna BD, Armour JA. Functional capacity of nicotine-sensitive canine intrinsic cardiac neurons to modify the heart. Am J Physiol 1994; 266: R1127-R1135.

48. Armour JA. Myocardial ischaemia and the cardiac nervous system. Cardiovasc Res 1999; 41: 41-54.

49. Foreman RD, Linderoth B, Ardell JL, Barron KW, Chandler MJ, Hull SS, Jr., et al. Modulation of intrinsic cardiac neurons by spinal cord stimulation: implications for its therapeutic use in angina pectoris. Cardiovasc Res 2000; 47: 367-75.

50. Wang ZW, Saifee O, Nonet ML, Salkoff L. SLO-1 potassium channels control quantal content of neurotransmitter release at the C. elegans neuromuscular junction. Neuron 2001; 32: 867-81.

51. Gribkoff VK, Starrett JE, Jr., Dworetzky SI, Hewawasam P, Boissard CG, Cook DA, et al. Targeting acute ischemic stroke with a calcium-sensitive opener of maxi-K potassium channels. Nat Med 2001; 7: 471-7.

52. Armour JA. Myocardial ischaemia and the cardiac nervous system. Cardiovasc Res 1999; 41: 41-54.

53. Kawaguchi M, Takahashi M, Hata T, Kashima $Y$, Usui F, Morimoto $H$, et al. Inflammasome activation of cardiac fibroblasts is essential for myocardial ischemia/reperfusion injury. Circulation 2011; 123: 594-604.

54. Reid AC, Brazin JA, Morrey C, Silver RB, Levi R. Targeting cardiac mast cells: pharmacological modulation of the local renin-angiotensin system. Curr Pharm Des 2011; 17: 3744-52.

55. Koda K, Salazar-Rodriguez M, Corti F, Chan NY, Estephan R, Silver RB, et al. Aldehyde dehydrogenase activation prevents reperfusion arrhythmias by inhibiting local renin release from cardiac mast cells. Circulation 2010; 122: 771-81.

56. Shah AP, Youngquist ST, McClung CD, Tzvetkova E, Hanif MA, Rosborough JP, et al. Markers of progenitor cell recruitment and differentiation rise early during ischemia and continue during resuscitation in a porcine acute ischemia model. J Interferon Cytokine Res 2011; 31: 509-13. 
57. Fretwell L, Dickenson JM. Role of large-conductance $\mathrm{Ca}^{2+}$-activated potassium channels in adenosine $A(1)$ receptor-mediated pharmacological preconditioning in H9c2 cells. Eur $J$ Pharmacol 2009; 618: 37-44.

58. Wang X, Yin C, Xi L, Kukreja RC. Opening of $\mathrm{Ca}^{2+}$-activated $\mathrm{K}^{+}$channels triggers early and delayed preconditioning against I/R injury independent of NOS in mice. Am J Physiol Heart Circ Physiol 2004; 287: H2070-H2077.

59. Singh H, Stefani E, Toro L. Intracellular BK $\mathrm{Ca}_{\mathrm{a}}\left(\mathrm{iBK}_{\mathrm{Ca}}\right)$ channels. J Physiol 2012; 590: 5937-47.

60. Piwonska M, Wilczek E, Szewczyk A, Wilczynski GM. Differential distribution of $\mathrm{Ca}^{2+}$ activated potassium channel beta4 subunit in rat brain: immunolocalization in neuronal mitochondria. Neuroscience 2008; 153: 446-60.

61. Skalska J, Bednarczyk P, Piwonska M, Kulawiak B, Wilczynski G, Dolowy K, et al. Calcium ions regulate $\mathrm{K}^{+}$uptake into brain mitochondria: The evidence for a novel potassium channel. Int J Mol Sci 2009; 10: 1104-20.

62. Ohya S, Kuwata Y, Sakamoto K, Muraki K, Imaizumi Y. Cardioprotective effects of estradiol include the activation of large-conductance $\mathrm{Ca}^{2+}$-activated $\mathrm{K}^{+}$channels in cardiac mitochondria. Am J Physiol Heart Circ Physiol 2005; 289: H1635-H1642.

63. Meera $\mathrm{P}$, Wallner $\mathrm{M}$, Toro L. A neuronal beta subunit (KCNMB4) makes the large conductance, voltage- and $\mathrm{Ca}^{2+}$-activated $\mathrm{K}^{+}$channel resistant to charybdotoxin and iberiotoxin. Proc Natl Acad Sci USA 2000; 97: 5562-7.

64. Chmielewska L, Malinska D. Cytoprotective action of the potassium channel opener NS1619 under conditions of disrupted calcium homeostasis. Pharmacol Rep 2011; 63: 17683.

65. Bednarczyk P, Barker GD, Halestrap AP. Determination of the rate of $\mathrm{K}^{+}$movement through potassium channels in isolated rat heart and liver mitochondria. Biochim Biophys Acta 2008; 1777: 540-8.

66. Heinen A, Camara AK, Aldakkak M, Rhodes SS, Riess ML, Stowe DF. Mitochondrial Ca ${ }^{2+}$ induced $\mathrm{K}^{+}$influx increases respiration and enhances ROS production while maintaining membrane potential. Am J Physiol Cell Physiol 2007; 292: C148-C156. 
67. Vanden Hoek TL, Becker LB, Shao Z, Li C, Schumacker PT. Reactive oxygen species released from mitochondria during brief hypoxia induce preconditioning in cardiomyocytes. J Biol Chem 1998; 273: 18092-8.

68. Murphy E, Steenbergen C. Preconditioning: the mitochondrial connection. Annu Rev Physiol 2007; 69: 51-67.

69. Garlid KD, Costa AD, Quinlan CL, Pierre SV, Dos SP. Cardioprotective signaling to mitochondria. J Mol Cell Cardiol 2009; 46: 858-66.

70. O'Rourke B. Evidence for mitochondrial $\mathrm{K}^{+}$channels and their role in cardioprotection. Circ Res 2004; 94: 420-32.

71. Hausenloy DJ, Yellon DM. Remote ischaemic preconditioning: underlying mechanisms and clinical application. Cardiovasc Res 2008; 79: 377-86. 
Figure 1

Figure 1
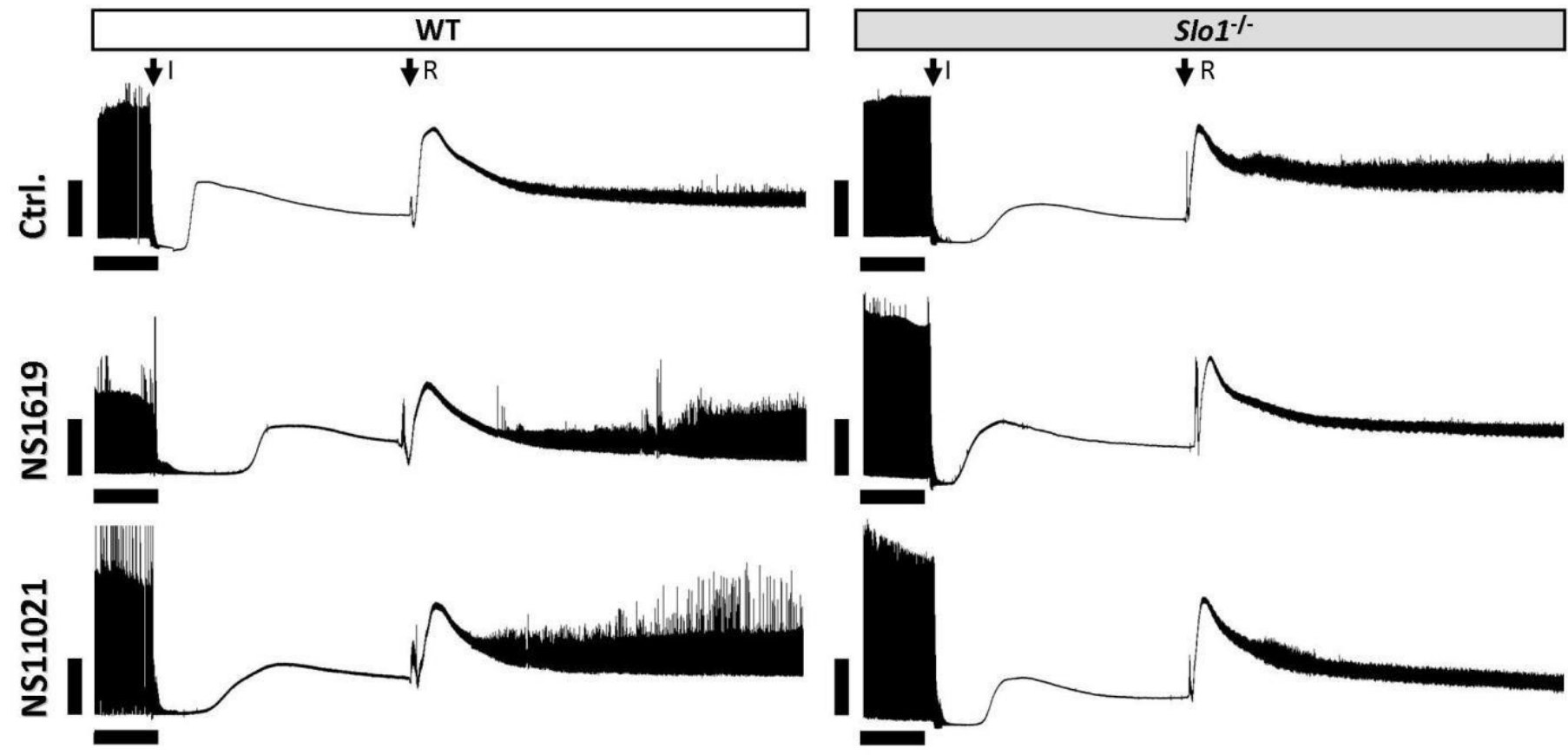
Figure 2

Figure 2
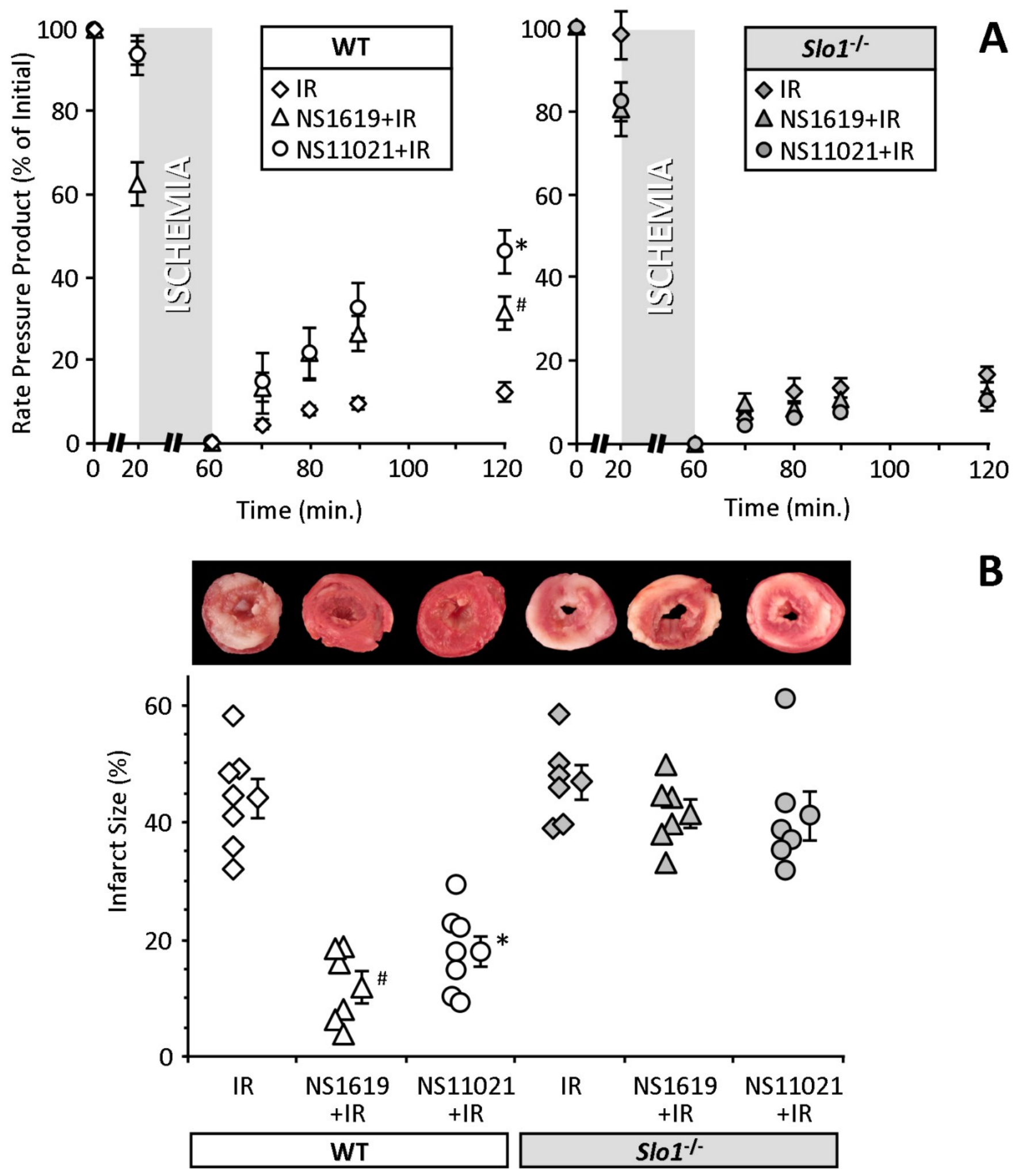
Figure 3

Figure 3

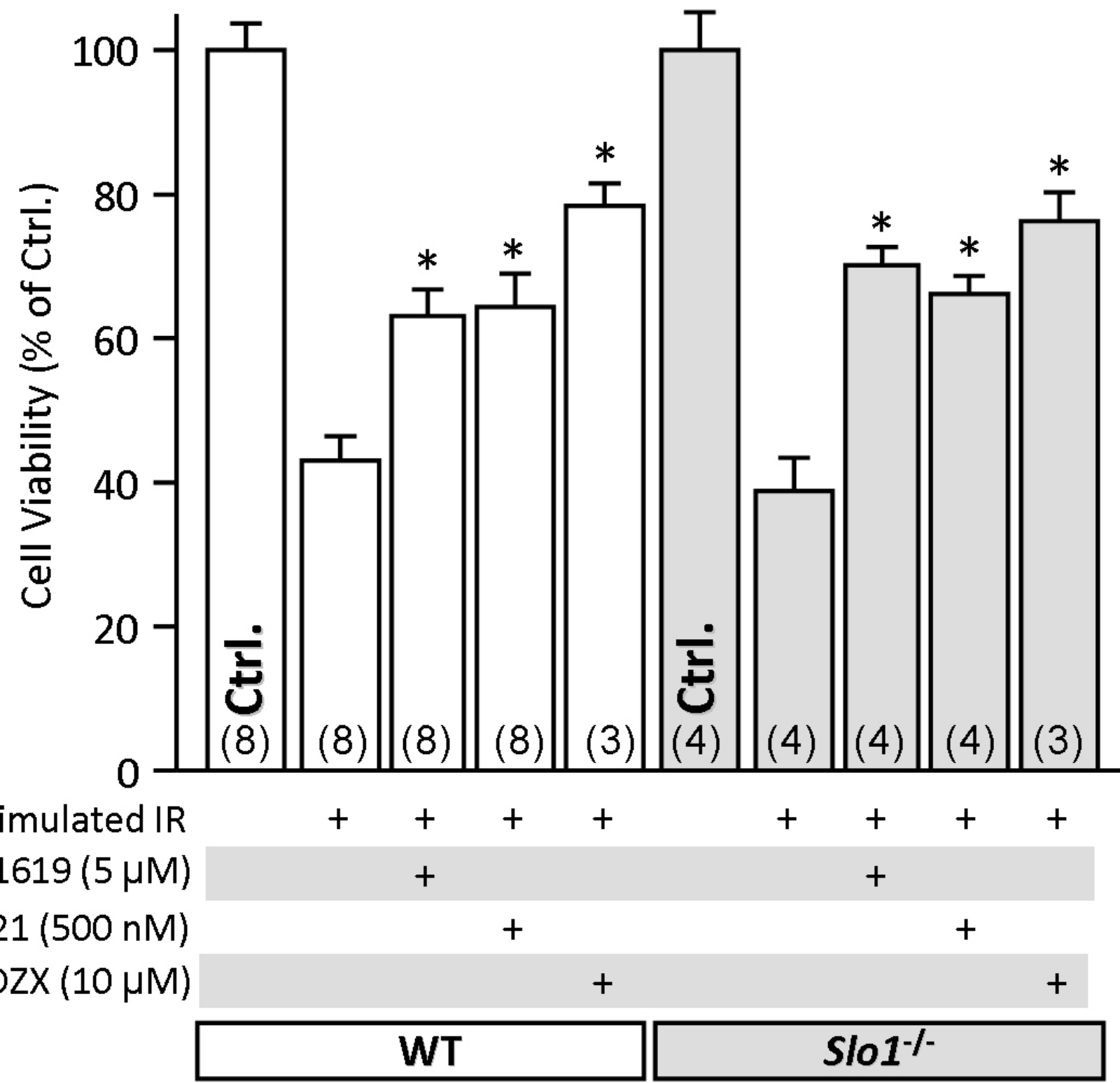


Figure 4

Figure 4 
A (mBK flux, NS1619, \pm Paxilline)

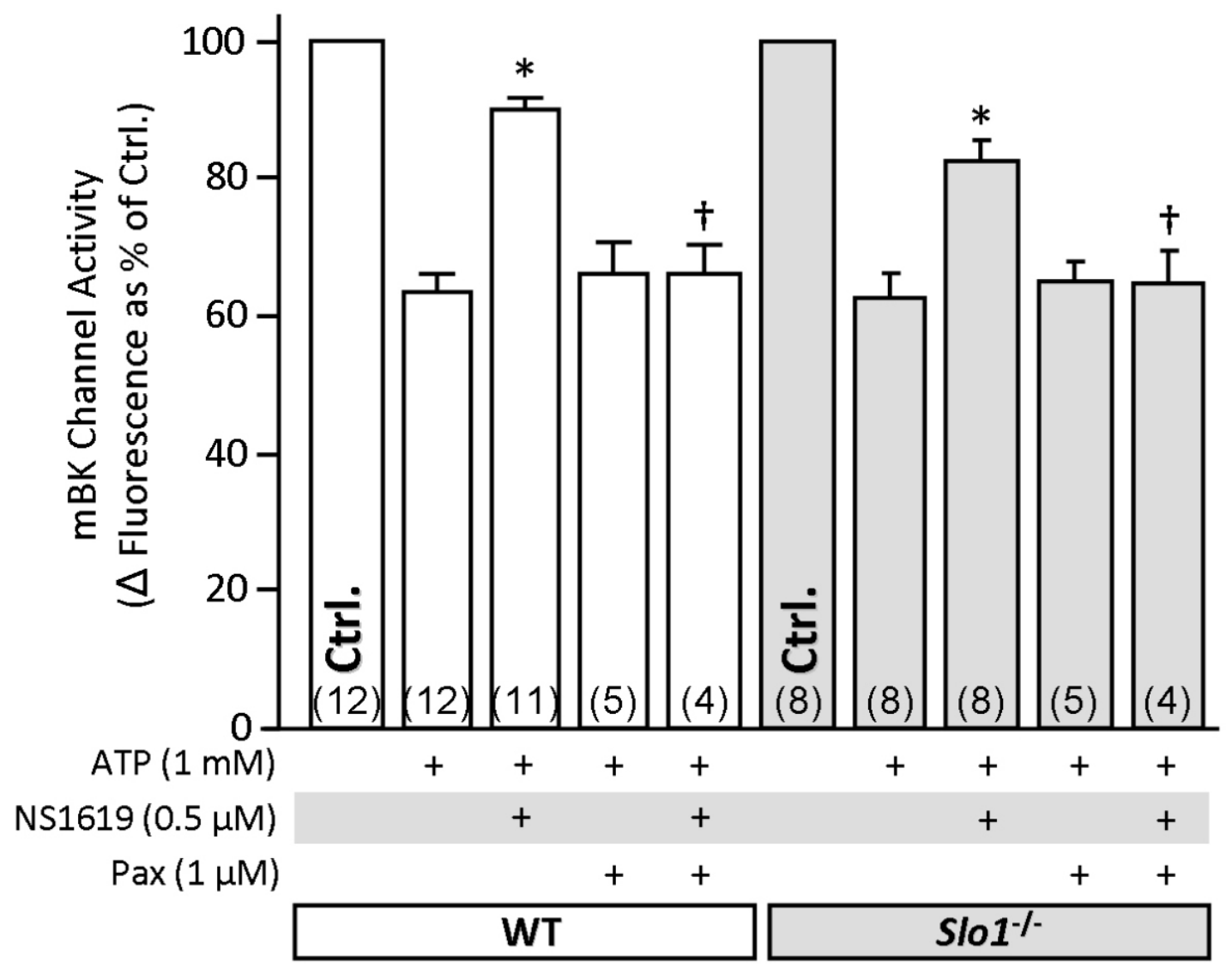

B (mBK flux, NS11021, \pm Paxilline)

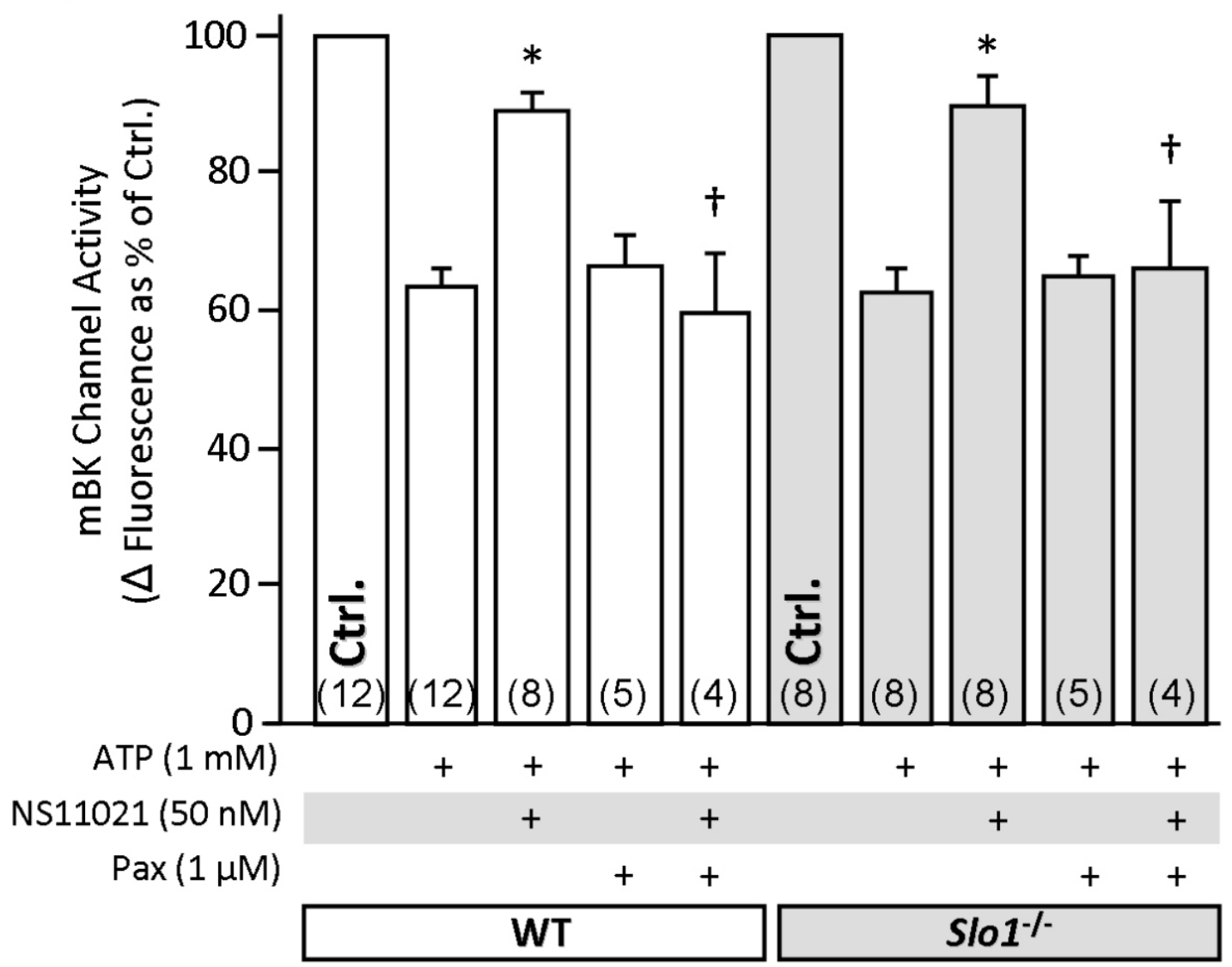


Figure 5

Figure 5
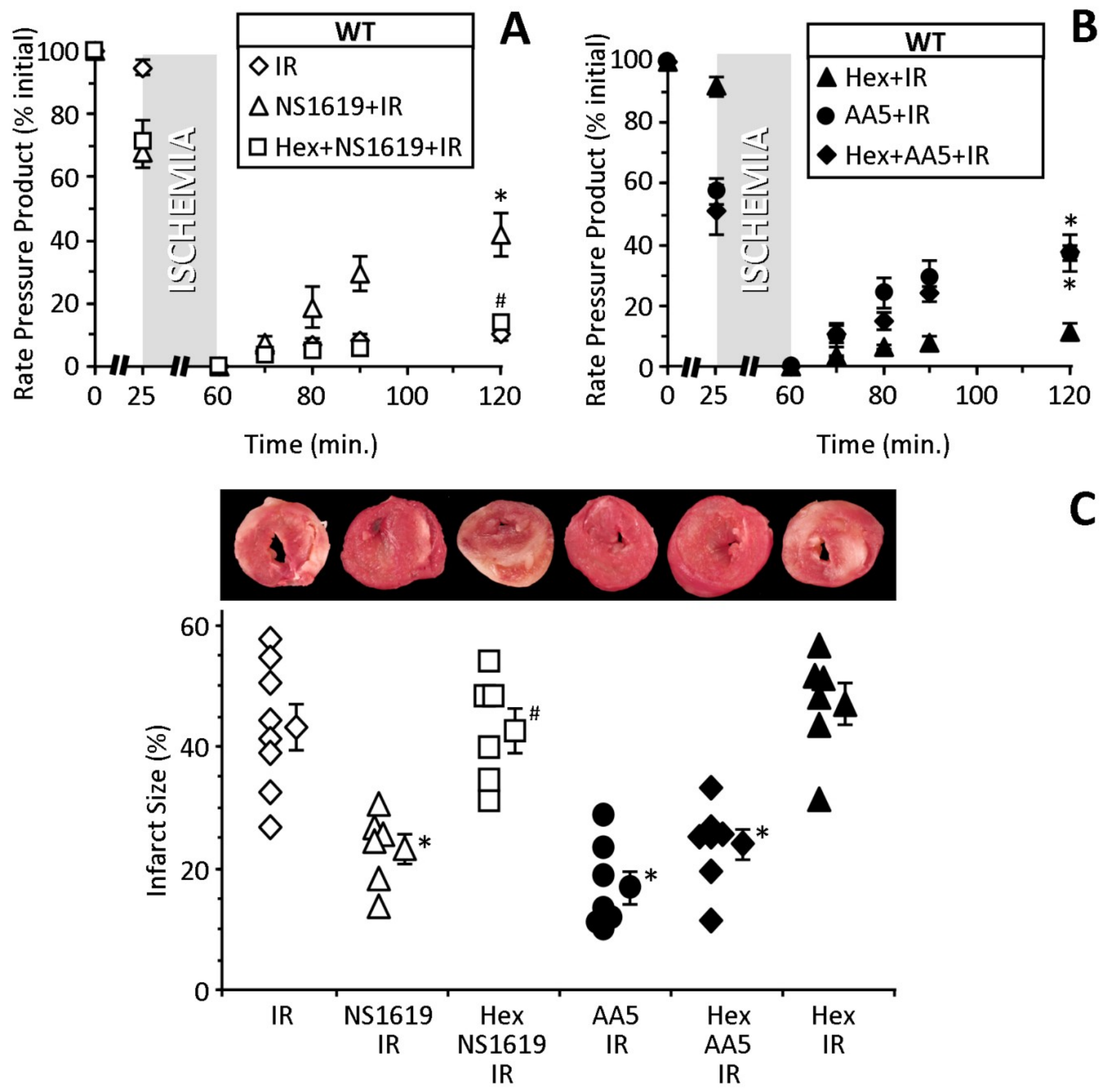
Figure 6

Figure 6 

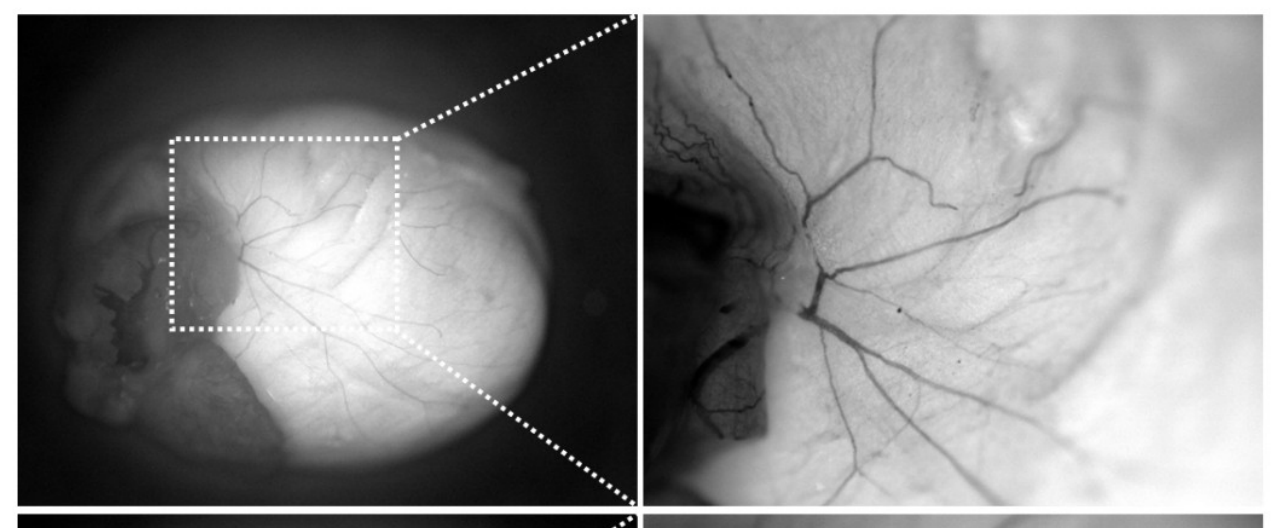

A
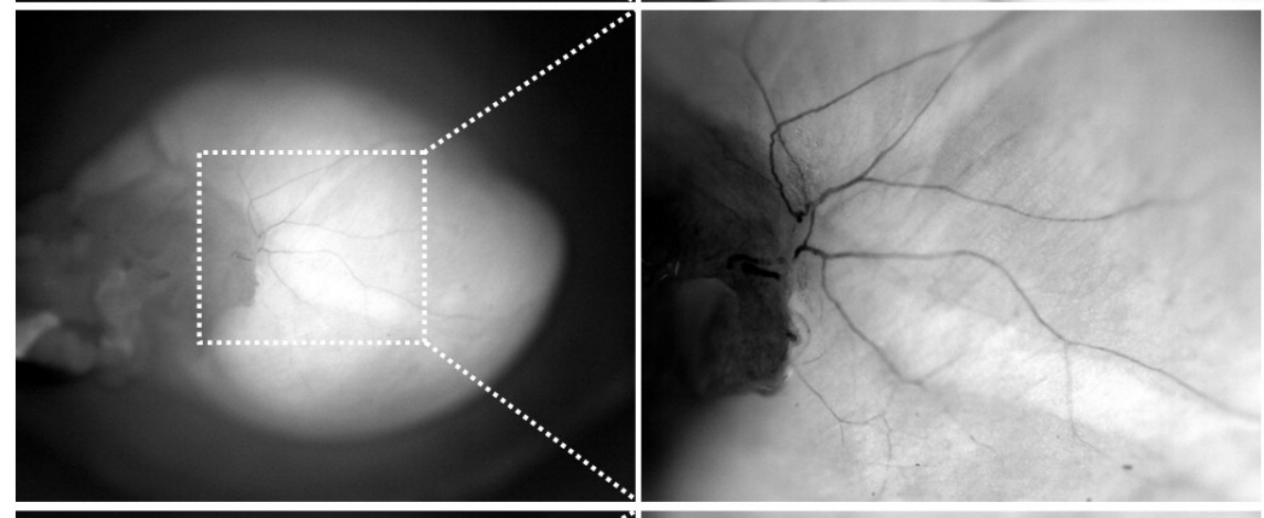

B
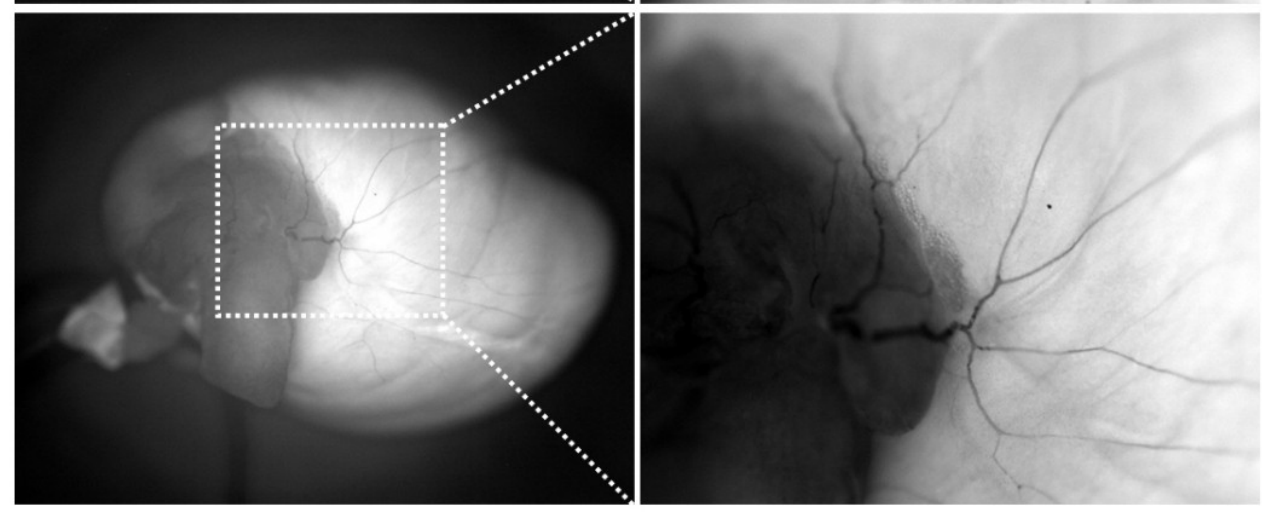

C
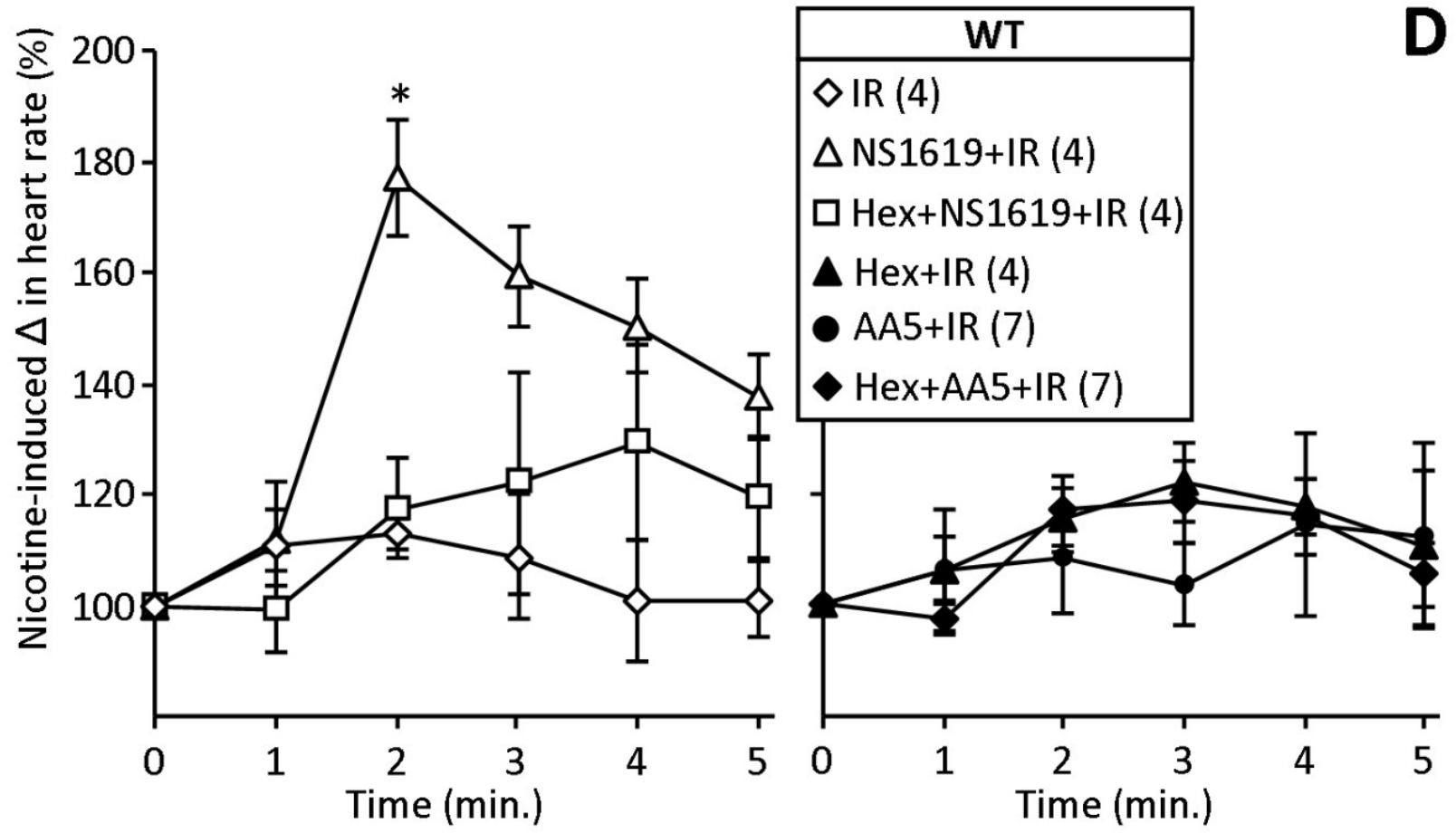
Figure 7

Figure 7

A Isolated Cardiomyocyte
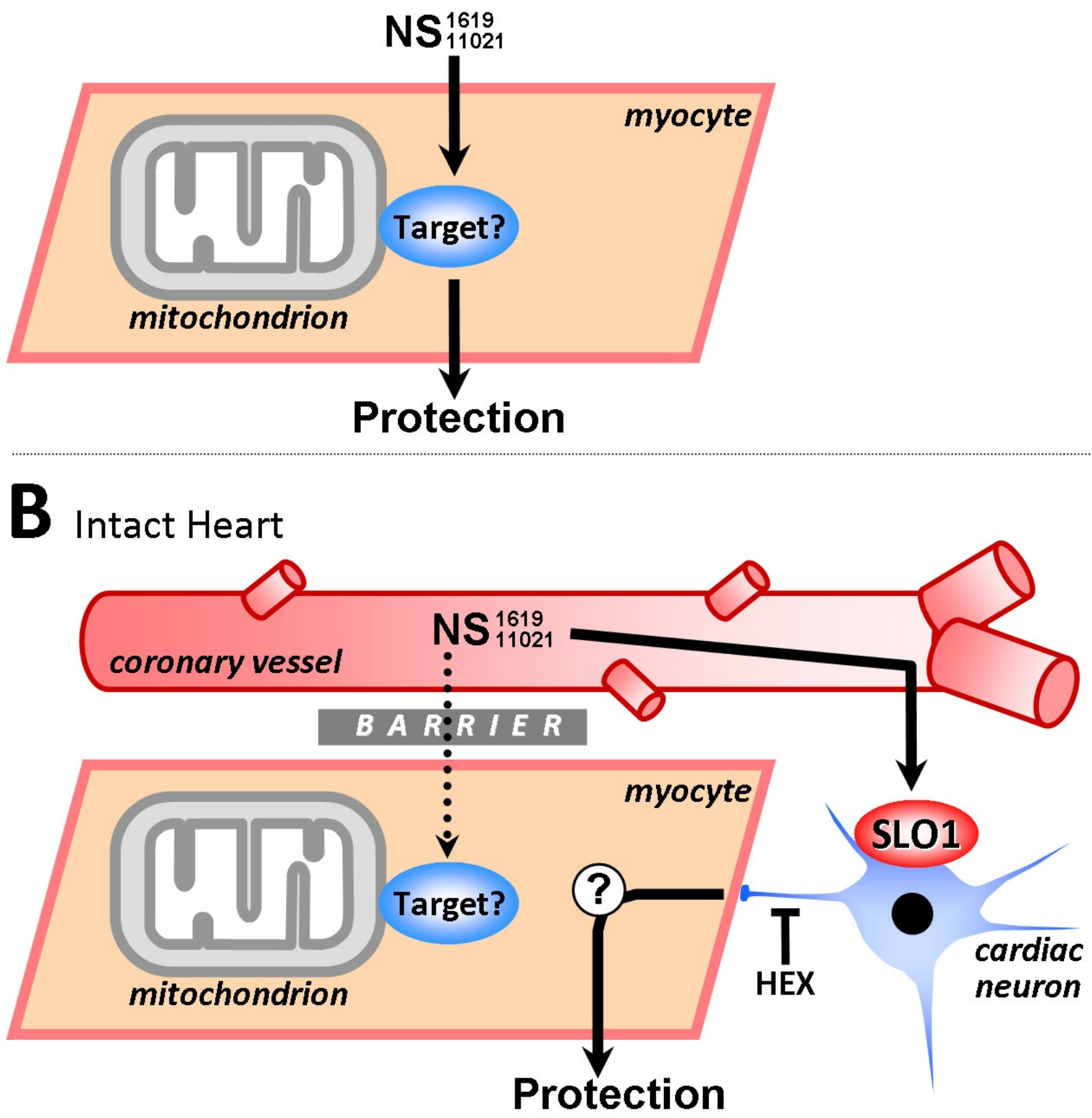